\title{
Scientific Literacy and the Future of Ethnic Minority Groups in the United States: The Unfinished Civil Rights Movement ${ }^{1}$
}

\author{
By Henry Lee Allen *
}

Science is humanity's best tool for unmasking intellectual gullibility. Scientific literacy possesses the knowledge or intellectual toolkit needed to understand how and why science relates to public issues in any society. It is distinct from technological literacy. According to a recent research of Hazen and Trefil (2009), 93\% of adults in the United States may not be scientifically literate, including $78 \%$ of college graduates and $74 \%$ of persons with graduate degrees. Outside the academic fields of their specializations, even renowned scientists can be scientifically illiterate. Unfortunately, scientific literacy is not a core topic for mass media or politics, despite its impact upon any society. Recently, in 20162017, the National Academy of Sciences in the United States has published salient reports about the need for and requirements of scientific literacy. Scientific literacy knows the basic concepts, theories, research findings, and implications or outcomes of physics, chemistry, biology, astronomy, and geology. For the purposes of this research, mathematics, complex systems science, computational science, and social sciences (plus network science) are included. The emphasis is on using knowledge, not creating it or doing science. Scientific literacy, at its best, leaves an indelible imprint for adventure, discovery, and wonder about the reality that engulfs all. This paper examines the vast research literature to dissect the status of scientific literacy among ethnic groups in the United States, probing the theoretical, methodological, policy-oriented, and practical implications of these results for the future of its social system and subsystems. Lastly, it proposes core elements of a tentative theory to explain scientific literacy.

Keywords: Conceptualization, Ethnic Minority Group, Science, Scientific Literacy.

Societies rise and fall based on their scientific prowess, energized inexorably by the intangible resources of scientific literacy that are often invisible, but invaluable, to populations (Royal Society, United Kingdom, 2010, 2011, Piel 2001, Boorstin 1983). Scientific literacy is a prelude to understanding and creating any scientific innovations for nations as well as their subpopulations (ethnic minorities). Within postindustrial societies, it affects technological developments, markets, democratic processes, public policy decisions, healthcare options, media savvy, military infrastructures, cybersecurity, and related domains (Otto 2016). Even religious dogmas and their interpretations are affected by scientific literacy (Alumkal 2017). Moreover, scientific literacy has global implications for the welfare of nations across generations (Ben-David 1984, Piel 2001). In short, scientific literacy is a powerful tool for safeguarding human and civil rights in

\footnotetext{
${ }^{*}$ Professor, Wheaton College, USA.

${ }^{1}$ This paper evolved from a presentation at the $4{ }^{\text {th }}$ Annual International Conference on Demography and Population Studies, June 13, 2017, Athens Institute for Education and Research.
} 
global societies (National Academy of Sciences, United States 2017b, 2016). It is the most important component of any social or human capital analysis. ${ }^{2}$ Science is the most indispensable tool for improving the ultimate welfare of citizens across generations in any society. We have yet to fully discover the many unpredictable, hidden ways that every society and their social networks have been improved by scientific literacy (Hunt 2007).

Scientific literacy possesses the knowledge or intellectual toolkit needed to understand how and why science relates to public issues and global concerns. ${ }^{3}$ It is distinct from technological literacy. According to recent research, 93\% of adults in the United States may not be scientifically literate, including $78 \%$ of college graduates and $74 \%$ of persons with graduate degrees (Hazen and Trefil 2009). Outside the academic fields of their specializations, even renowned scientists can be scientifically illiterate (Trefil 2008). Unfortunately, scientific literacy is not a core topic for mass media or politics, despite its impact upon any society (Volti 1992).

Scientific literacy knows the basic concepts, theories, research findings, and implications or outcomes of physics, chemistry, biology, astronomy, and geology. For the purposes of this research, mathematics, complex systems science, computational science, and social sciences (plus network science) are included. The emphasis is on using knowledge, along with creating it or doing science. Scientific literacy, at its best, leaves an indelible imprint for adventure, discovery, and wonder about the reality that engulfs all (Wolfram 2002). No ethnic group in any society can achieve optimal civil or human rights without the predominance of scientific literacy among its population within its social system (Estrada 2012, Wagner 2008, Boorstin 1983). But, without question, certain ethnic groups in the United States have suffered across generations from interpersonal dynamics (unscientific prejudice, discrimination, oppression, and xenophobia), structured social pathologies, ideological myths, as well as, inept social and justice policies that have atrophied the development of authentic scientific literacy (Cole and Cole 1973). To correct such wasted potential is a twenty-first century imperative for astute scientists everywhere (Gould 1996).

This paper examines the vast research literature to dissect the status of scientific literacy among ethnic groups in the United States, probing the theoretical, methodological, policy-oriented, and practical implications of these results for the future of its social system and subsystems. It focuses upon pivotal insights and data published by

- the United Nations (UNESCO 2010, 2016)

- the Royal Society (United Kingdom)

- the National Academy of Sciences (United States)

- the National Center for Education Statistics (United States)

- Wolfram Research, think tanks (such as the Pew Research Center)

\footnotetext{
${ }^{2}$ Every scientific innovation is a function of human social networks (Barabasi 2016, Nielsen 2012, Estrada 2012, Christakis and Fowler 2009, Wagner 2008)

${ }^{3}$ As we contemplate scientific literacy, we must cultivate its depth and breadth in society.
} 
- The most salient articles from premier research journals, philanthropic foundation reports, and a webinar by Sage Publications.

First, we examine why scientific literacy always matters in every society, regardless of its political structures, economic system, and cultural proclivities. Secondly, we dissect conceptualization and measurement matters relevant to studying scientific literacy, especially among ethnic groups in the United States. Thirdly, out of a much more voluminous literature, we scrutinize a select sample of empirical findings related to scientific literacy and the aforementioned groups. Fourthly, we deduce relevant scientific implications, incorporating the elements of an evolving theory. Conclusions follow.

\section{Why Scientific Literacy Always Matters}

Why is scientific literacy so crucial for human survival in any viable society or community? Beyond enshrining and institutionalizing the rule of evidence, peer review, and falsification procedures, Table 1 below presents a limited set of crucial reasons.

Table 1. A Selective List of Salient Impacts of Scientific Literacy (SL)

\begin{tabular}{|l|l|}
\hline $\begin{array}{l}\text { Unit of } \\
\text { Analysis }\end{array}$ & \multicolumn{1}{c|}{ Salient Impacts of Scientific Literacy (SL) } \\
\hline Economy & $\begin{array}{l}\text { SL is an essential prelude to technological innovations and economic } \\
\text { development (Mazzucato 2013) }\end{array}$ \\
\hline Democracy & $\begin{array}{l}\text { SL gives viability to authentic education and competencies for problem- } \\
\text { solving (Weinberg 2015, Best 2011) }\end{array}$ \\
\hline Civil Society & $\begin{array}{l}\text { SL generates and guarantees the rigorous expertise that validates genuine } \\
\text { freedom (Otto 2016) }\end{array}$ \\
\hline $\begin{array}{l}\text { Social } \\
\text { Welfare }\end{array}$ & $\begin{array}{l}\text { SL is the prime impetus for intergenerational mobility for ethnic groups, } \\
\text { professions, organizations, and occupations (Simon 1996, 1995, 1957) }\end{array}$ \\
\hline $\begin{array}{l}\text { Social } \\
\text { Policies }\end{array}$ & $\begin{array}{l}\text { SL improves policy outcomes for governments and communities (Boyd } \\
\text { and Iverson 1979, Carroll and Hannan 2000) }\end{array}$ \\
\hline Health & $\begin{array}{l}\text { SL affects the health and medical care of peoples and societies (Barr } \\
\text { 2014, Berkman and Kawachi 2000) }\end{array}$ \\
\hline Populations & $\begin{array}{l}\text { SL is a society's best protection against racist idiocy, patriarchal jingoism, } \\
\text { political or ideological stupidity, and religious dogmatism (Gross et al. } \\
\text { 1996, Gross and Levitt 1994, Blalock 1984, 1982, 1969, 1964, Blalock } \\
\text { and Wilken 1979) }\end{array}$ \\
\hline Mass Media & $\begin{array}{l}\text { SL reveals overt and covert propaganda, the tyranny of majorities, plus } \\
\text { inconspicuous manipulations in symbols or images (Byers 2015, 2011, } \\
\text { 2007) }\end{array}$ \\
\hline
\end{tabular}

To reiterate, scientific literacy is instrumental to economic development, technological prowess, intelligent democratic deliberations, safeguarding freedoms, improving social outcomes or policies, producing healthy citizens, fighting social viruses, and correcting falsities based upon petulant or sinister 
vested interests. To some, such power is threatening, while to others it is liberating. We have yet to establish the incidence of scientific literacy within (intragroup social networks) or across (intergroup social networks) specific ethnic populations (National Academy of Sciences 2010).

What then can we learn about scientific literacy from pivotal reports recently issued by the United States National Academy of Sciences? ${ }^{4}$ In 2016, the National Academy of Sciences (NAS) released a major report about scientific literacy in the United States (National Academy of Sciences 2016). Essentially, they reasoned that scientific literacy is not just an individual asset, but rather a vital community resource in a complex society (National Academy of Sciences 2016). ${ }^{5}$ It consists of: (1) an appreciation for science; (2) a general understanding of its scope and promise; (3) a trust in its endeavors; (4) a realistic knowledge of its impact within social organizations or associations; and (5) tangible insight regarding how scientists produce empirical evidence and robust explanations. In sum, the report views scientific literacy as a social process with content shaped by contextual factors across and within communities. Foundational literacy, social structures, systemic factors, attitudes, and disparities all interact to generate scientific literacy in unknown ways at present. The authors of the report caution that existing research does not validate the notion that increasing scientific literacy automatically increases support for science (NAS 2017a).

In 2017, NAS (2017b) published a second crucial report about communicating science more effectively. Here, they invite researchers to probe effective methods or strategies for communicating the excitement of scientific investigation, for helping communities comprehend scientific findings, and for engaging diverse communities in the scientific realm. Once again, social factors were stressed explicitly, along with impediments related to the complications of learning science and processing its results. Of course, all of the aforementioned factors affect the formation, execution, and implementation of societal policies. The findings of both NAS reports are far too voluminous to be captured fully in this brief venue. Suffice it to say that exploring the inculcation of SL among ethnic minority groups is essential to scientific proficiency and innovations in the future. SL is a prelude to proficiency. ${ }^{6}$

Other global research echoes concern about the salience of science (scientific literacy) in society. The United Kingdom's (UK) Royal Society has spent much of the decade accentuating the role of science, and thereby SL, in society (Royal Society 2010). They established conclusively that the welfare of society was inextricably contingent on nurturing scientific prowess and enlarging its capacity. From their careful findings, we can observe that: (1) "The UK produces more publications and citations per pound spent on research than any other G8 nation;" (2) "With $1 \%$ of the world's population, the UK produces $7.9 \%$ of the

\footnotetext{
${ }^{4}$ Technically, the authors of the report prefer the term "science literacy" while acknowledging the nomenclature used by this author.

${ }^{5}$ The report reveals numerous technicalities and core research questions that must be explored to understand SL. While acknowledging methodological problems, it accentuates the strategic role of the social sciences.

${ }^{6}$ Scientific proficiency (competence) in individuals, communities, and societies takes time, the result of a prolonged developmental process as well as serendipitous outcomes.
} 
world's publications, receives $11.8 \%$ of citations, and $14.4 \%$ of citations with the highest impact;" and, (3) the UK is "now a net importer of scientists and innovators, and these people are more highly skilled than ever before." Celebrating 350 years of existence, in other publications, the Royal Society has lobbied for increased funding, future planning, neuroscience, and the fecundity of global scientific networks worldwide. In short, SL has dire international repercussions for the welfare of nations and communities (and their ethnic minority groups). To gain a much bigger, global picture, what can we simply learn from UNESCO's research? To survive and thrive, the nations of the world must harvest scientific literacy in their populations or attract those who have acquired it from somewhere else (UNESCO 2016, 2010).

Yet, according to Otto (2016) and others, ethnic minorities will face considerable challenges to pursue authentic science. He encapsulates threats to SL in the United States:

The vanguard of the retreat (from science) is in the Western democracies, where Christian fundamentalists; postmodern academics, teachers, and journalists; liberal new age purists; and industry front groups all attack science for their own reasons (Otto 2016: 7).

Moreover, policy makers in the United States have minimal competencies in science (Otto 2016):

- Fewer than $1 \%$ of persons in the Congress have professional backgrounds in science, while about $40 \%$ have law degrees. ${ }^{7}$

- Legal thinking is anchored in precedent, not discovery; in selective argument, not the relentless pursuit of truth; of legality, not theory.

- On the political right, science is diluted and polluted by cascades of disinformation, along with toxic propaganda from vested corporate interests or anti-science churches.

- On the left of the political spectrum, the quest for truth or facts in science is mocked by a penchant for relativism, sophistry, and unrealistic suspicions.

- Journalists often favor impressionistic, sentimental stories (narratives) over refutation, and sensationalism over meticulous sustained inquiry.

- Political leaders are often in denial about the scientific, technological infrastructure, sabotaging its needs and future for the immediate gratification of votes (or lobbyists). They fail to understand that "science was responsible for more than half of all U.S. economic growth since World War II. It lies at the core of most major unresolved policy challenges the world over." Otto cites 14 scientific arenas facing the nation.

\footnotetext{
${ }^{7}$ Otto comments: "So it's little wonder that we see more rhetoric than facts in global policymaking." (p. 11)
} 
Otto is not alone in his substantive concerns. Likewise, Alumkal (2017) indicts several religious factors impeding the diffusion of SL in the United States. Within the Christian Right, he sees fear, paranoia, apocalypticism, and several logical fallacies as posing lethal threats to science. False dichotomies (dualism), slippery slope thinking, and the straw person fallacy inhabit religious dogmatism in many fundamentalist or evangelical circles. All are ingredients in a recipe of myopia or intellectual glaucoma (Alumkal 2017: 4-15).

\section{Theoretical Issues: Conceptualization and Measurement}

According to Hazen and Trefil (2009), less than $7 \%$ of U.S. adults can be deemed scientifically literate. Thus, $93 \%$ of the adult population is scientifically illiterate! They submit also that $78 \%$ of college graduates and $74 \%$ of those with graduate degrees have the same limitation (Hazen and Trefil 2009: xvxvii). Invariably, these realities influence political intelligence and savvy, engagements with natural and physical phenomena, and educational progress. Even working scientists can be grossly illiterate outside their own field of expertise (Hazen and Trefil 2009: xiii). SL moves thinking beyond what is trite, bizarre, or quaint across populations and generations. ${ }^{9}$ Science requires multiple levels, dimensions, and types of thinking that transcend popular discourses. ${ }^{10}$ Invariably, skepticism and parsimony are endemic to acculturation in science. Thus, scientific literacy entails a cognitive toolkit that is different from other nonscientific pursuits (Otto 2016: 3-42). SL challenges confirmation bias and other logical fallacies. It defies deterministic thinking or mere propositional schema, especially specious or spurious logics and evidence. Most importantly, SL refutes "ex post facto" arguments that are so prevalent in political, legal, and cultural discourses. SL exposes anti-scientific pretensions and distorted facts, so ubiquitous with vested interests wherever or whenever they surface. SL is a bulwark against anti-intellectualism, dogmatism, fundamentalism, authoritarianism, and an incipient ethnocentrism. In short, science is global humanity's best antidote to sophistry and delusions (Thompson 2008, Gross and Levitt 1994, Gross et al. 1996).

Decades ago, sociologist C. Wright Mills urged scholars in the United States to begin their analysis by focusing on the history, biography (identity), and social structure that generates intragroup and intergroup relations. Every ethnic group has a history that has generated its evolutionary development or social attainments. These phenomena must be integrated someway, somehow, in any serious scientific study beyond reductive linear conceptualizations and

\footnotetext{
${ }^{8}$ In the current political climate within the United States (Trump presidency), SL can identify obfuscation, subterfuge, and pugnacious rhetoric among government officials and pundits.

${ }^{9}$ SL must be carefully distinguished from "scientism," the naive or mystical belief that science is a panacea for all things. Likewise, SL is not equal to "scientific proficiency", a professional outcome that entails rigorous competencies that are cognitive, tacit, experiential, and reflexive.

${ }^{10}$ For example, observational, empirical (qualitative, quantitative, or both), computational, and mathematical as well as their interrelations plus contingencies. At it most optimal capacity, SL involves basic (theoretical) as well as applied (empirical) domains of inquiry and their interactions.
} 
measurements (Boyd and Iverson 1979, Miller and Page 2007, Batty 2005, Bailey 1994). Regarding the conceptualization of ethnicity, Feagin (1994) targets 6 factors essential to analyzing ethnic groups and their identities. Figure 1 below illustrates these core social factors, while Table 2 incorporates them into a much larger conceptual matrix associated with Mills' schema for the social imagination.

In sum, Feagin insists that we probe how ethnic groups come together and interact socially in tangible environments (migration, adaptation). Such patterns of social interaction can yield a range of conflicts and stereotypes over time. These complex adaptations generate distinct patterns of incorporations with structured social institutions, thereby affecting ethnic identities across generations. See Figure 1 below.

Figure 1. Feagin's Criteria for Analyzing Ethnic Groups in the United States

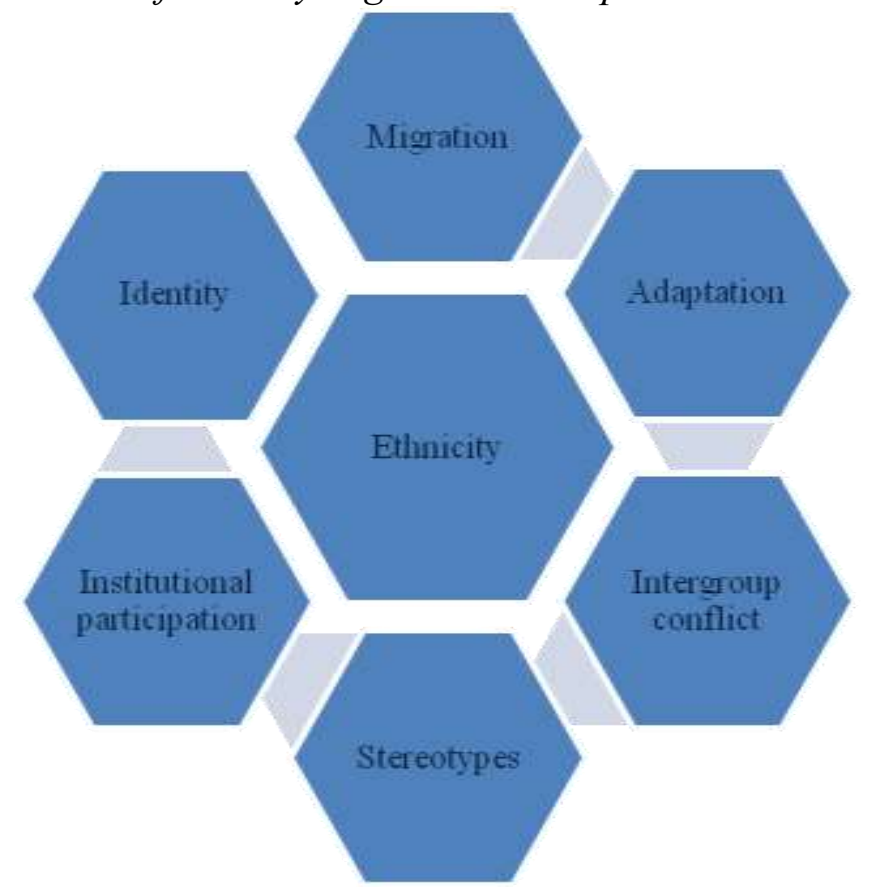

By adapting Feagin's typology to the quest for SL, the following questions are germane:

1. Why and how do various ethnic groups in the United States engage SL?

2. What conditions [interpersonal, structural (institutional), ecological, contextual, etc.] attract them to SL or contribute to repulsing their pathways to SL?

3. Do sufficient, effective exemplars, images, incentives, resources, and so forth exist to counteract conflicts or stereotypes that impede SL?

4. What struggles, biases, or conflicts must be dissected and remedied in developing SL?

5. What historical barriers (and their after-effects) dilute SL for particular ethnic groups across social networks and institutionalized spaces? 
6. What fresh, new inducements or policies must society innovate to connect ethnic groups to SL for the rest of the twenty-first century?

These and similar questions are at the frontiers of SL, as indicated in recent research. Almost 70 years after the dawn of the Civil Rights Movement in the United States and despite popular rhetoric about equality of opportunity, SL has not been achieved for many ethnic minority groups, partly because our scientific knowledge is so inauspicious and inadequate. As indicated in Table 2 below, C. Wright Mills anchored sociological analysis across the dimensions of history, biography (ethnic identity), and social structure. Yet, Table 2 below invokes other conceptual and methodological topics of concern to close the gaps related to SL, including complexity science, evolutionary plus behavioral game theory, organizational demography, mathematical and computational modeling. The scope of these ideas exceeds the capacity of this article, but these vast phenomena require a new type of social science in the future (Padgett and Powell 2012).

Table 2. A List of Essential Social Factors Involved in Conceptualizing SL among Ethnic Minority Groups in the United States

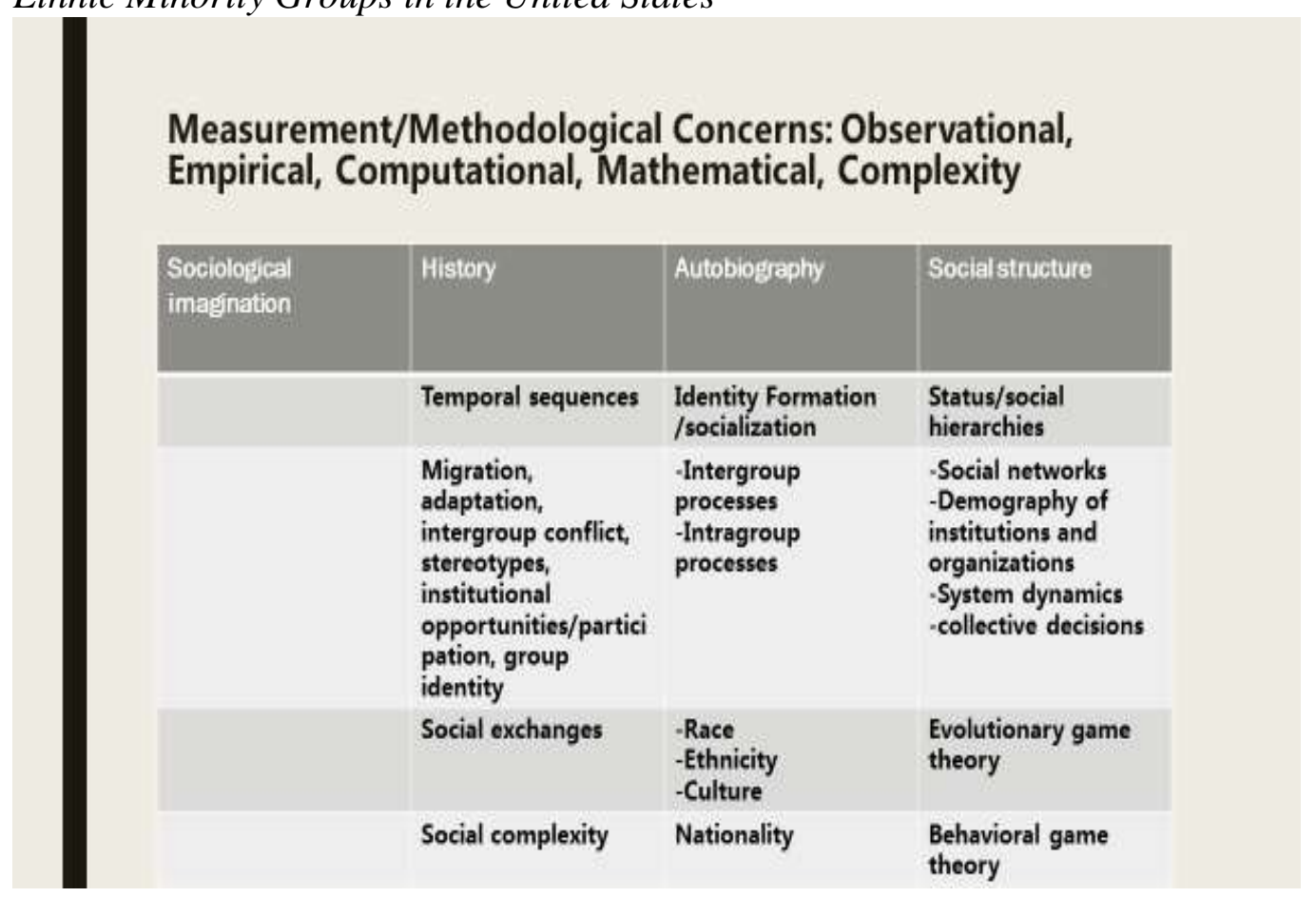

Using a very simple conceptual rubric, the above chart indicates the plethora of items and variables necessary for analyzing the interconnections between SL and ethnic disparities. 


\section{Empirical Findings Regarding SL and its Social Contexts}

William Frey (2015), a renowned demographer at Brookings Institution, has made key observations about ethnic diversity from extensive data tables throughout his book, Diversity Explosion. First, the United States is entering a "turbulent period" as it shifts from being dominated by an older "white" population characterized by persons of European ancestry or immigration toward incorporating younger cohorts of "minority" or ethnically diverse groups. Secondly, this turbulence produces different propensities geographically and distinct constellations within institutional sectors. Thirdly, biracial and multiracial persons have increased across the country. Fourthly, life chances, consumerism, schooling, employment, residential patterns, and patterns of consumption are differentiated among cohorts and ethnic groups. Hispanic and Asian populations are increasing rapidly. Segregation for many African Americans remains salient. Meanwhile, "white" populations have become more institutionalized in private rather than public schools. Education access, wealth, and opportunities are clearly not equal, nor have they ever been. Disparities in these resources affect SL.

The Pew Research Center has documented, via survey research, minority group disparities in science knowledge (Pew Research Center 2015a). Researchers solicited responses to a series of 12 science-related items. They have concluded: (1) education affects SL for all ethnic groups; (2) observed differences are evident at elementary and high school levels; and (3) these differences affect life chances: employment, income (wealth), etc. Again, no definitive explanation was established regarding how SL is generated among diverse groups. Differences in educational access, institutional distributions, mentoring and sponsoring opportunities, visibility, and workforce participation in science-related careers were touted as plausible reasons for observed disparities, more than five decades after the Civil Rights Movement and affirmative action policies. There is no evidence of systemic "reverse discrimination" here. Noticeably, the social sciences were omitted altogether from this research. According to this sociologist, SL would be even worse if public responses to these sciences had also been studied. $^{11}$

Moreover, extensive sociological research continues to find acute empirical evidence regarding hyper-segregation, gross inequalities, misguided social policies, patterns of disinvestment, etc (Caliendo 2015, Sharkey 2013, Holzman 2014). Recent reports by the National Center for Education Statistics (NCES), the Southern Education Foundation, and others reveal institutionalized, segregated levels of deprivation, disparities, and disadvantages that have negative epidemiological effects upon ethnic minority groups. ${ }^{12}$ For brevity's sake, the

\footnotetext{
${ }^{11}$ Out of curiosity, for example, do distinct, recurrent regional differences in SL exist in the United States? If yes, what social networks and other factors are generating such outcomes for SL? For which groups? Why? These questions require multidimensional empirical inquiry and evidence across varying conditions and time periods.

${ }^{12}$ University of Illinois-Chicago, Institute on Race and Public Policy 2017; Shapiro et al. 2017, National Center for Education Statistics 2016, Harvard Business School 2016, American Council on Education 2015. Southern Education Foundation 2013.
} 
reader must access these data elsewhere. Table 3 highlights a few poignant matters, citing relevant background factors that inhibit SL. More important than these traditional tabulations is the lack of social network data on how these data are generated as well as the paucity of research on the political economy of social contexts (Castellani and Hafferty 2009). To wit, social systems - large or small — have multidimensional consequences that inexorably enhance or inhibit SL. Like radiation, these social consequences and ethnic group disparities are intergenerational as well as precarious. How one could govern an evolving, complex society apart from robust levels of SL in the populace astounds and confounds any sane logic. Only regressive mindsets would attempt such idiocy. As Albert Einstein said wisely decades ago "problems cannot be solved at the same level of awareness (expertise) in which they were created".

Table 3. Select Research Findings for Ethnic Minority Groups in the United States

Southern Education Foundation (2013):

--"The nation's cities have the highest rates of low income students in public schools. Sixty percent of the public school children in America's cities were in low income households in 2011."

--In 2011, for all public schools, $72 \%$ of Black, $68 \%$ of Hispanic, and $65 \%$ of American Indian/Alaska Native students attended public schools where low income students are half or more of all students, compared to $30 \%$ of white students and $35 \%$ of Asian students.

Institute for Research on Race and Public Policy (2017): a case study of Chicago, IL

--"The central finding of this report is that racial and ethnic inequities in Chicago remain pervasive, persistent, and consequential. These inequities affect the lives of Chicagoans in every neighborhood: they have not just spatial but also deep historical roots and are embedded in our social, economic, political, and cultural institutions; and they have powerful effects on the experiences and opportunities of all Chicagoans."

--"Large racial and ethnic inequalities in resources persist at all class levels. For instance, education attainment does not alleviate racial inequalities in unemployment of income."

National Center on Education Statistics (2016):

--Achievement levels differ among racial and ethnic groups, and gaps between groups at age 12 have widened since 1992.

American Council on Education and American Association of University Professors (2000):

--The existing scholarship consistently shows that racial and ethnic diversity positively affects the educational outcomes and experiences of college students.

Harvard Business School (2016):

--"Over the last several decades, however, the rate of investment in those parts of the commons on which the average American depends slowed down markedly."

Signature Report No. 12b (2017):

--inequities in postsecondary college completion rates highlight the need for higher education stakeholders to design initiatives aimed at increasing participation and ameliorating racial disparities.

Pew Research Center (2015):

--"Those with higher education levels are more likely to know answers to questions about science. There are also times when gender, age, race and ethnicity matter."

Under optimal conditions, SL could rescue any multiethnic and other societies from these ongoing catastrophes of stupidity, violence, injustices, and inequalities (Smith et al. 2017, Sinatra and Hofer 2016, Porter et al. 2009, Bybee 2009, 
Scearce 2007, Brandt 2007, Tate 2004, Pattison 1993). It permits us to fight "intellectual terrorism." SL research has an urgent need to produce a "scientific co-efficient", a computational algorithm, or mathematical model for modal trends affecting each ethnic group or subpopulation in the United States.

Our planet desperately needs a far more sophisticated SL in the social sciences than what we have now. Yet, many generations of social scientists and other scholars have contributed useful ideas for connecting SL to ethnic disparities in the United States (Page 2007, Feagin 1994, Blau 1994, Wallace 1983, Blalock 1969). Various conceptualization and measurement issues remain at the frontiers of discovery (Carley and Newell 1994). Recently, to correct an inexorable theoretical gap, Nobel Laureate (Economics) Joseph E. Stiglitz and Karla Hoff (2016) have integrated a range of social sciences in explaining the social determinants of behavior (Hoff and Stiglitz 2016). They incorporate enculturated actors whose mental or decision-making models exist within various social contexts and conditions that must contemplated in order to explain any social phenomena robustly. Although the implications of their schema are beyond the scope of this effort, the rudiments of a scientific theory relating SL to ethnic disparities seems much more plausible.

\section{Implications and Conclusions}

"Although social scientists still describe more than they measure, they are becoming dependent on mathematics. Some of the techniques they find most useful have been developed in recent years, and in the future their problems will very likely inspire much new mathematics. Mathematically speaking, the social sciences are likely to be far more difficult than physics."

John Kemeny 1969

How might interested or creative scholars at ATINER develop a systematic theory of how SL affects a society and its ethnic minority groups? ${ }^{13}$ Can models from the natural sciences assist in this quest, along with methodologies favored in the social sciences? Is it possible to conceptualize types of institutions as cellular automata facilitating SL across various phases? Is it possible to dissect the layers of social networks (or invisible colleges) affecting SL, directly or indirectly, overtly or covertly? Is game theory a factor in explaining how and why ethnic groups interact with SL? More boldly, what are the mathematical, computational, empirical, and observational interrelations between the domains or dimensions of institutions, networks, and decisions (game theory)? Can SL across ethnic groups and nations be analyzed by models adapted from simulated annealing? Do institutions reproduce themselves in ways that can be measured

\footnotetext{
${ }^{13}$ My fledgling efforts have begun by revisiting and extending the formulations of the late Nobel Laureate John Nash about game theory, especially as his mathematical insights might apply to cooperative and non-cooperative groups (or social networks) inculcating SL. Moreover, Nobel Laureate Herbert A. Simon has contributed salient ideas about organizations and markets.
} 
by genetic algorithms? Yes! Note the possible elements of a preliminary theory of scientific/academic systems and its implications for S.L.: cellular automata [institutions], social networks [invisible colleges], game theory [including evolutionary (Bowles 2004) plus behavioral (Camerer 2003, Young 2001) approaches], simulated annealing, and genetic algorithms. ${ }^{14}$

Let us constructively delimit the scope of our conceptualization and measurement by assuming that colleges and universities are the prime institutions responsible for generating SL. In the United States, for example, every social or academic system may be analyzed mathematically by incorporating the following concepts:

- All social systems are comprised of social agents (Carley and Newell 1994), subject to intragroup and intergroup processes (Blalock and Wilken 1979, Blalock et al. 1975). Social ties (direct and indirect) are embedded in social networks that are visible (formal) or invisible (informal) to observers (Valente 2010, Borgatti et al. 2009, Christakis and Fowler, 2009). These agents have varying capacities, interests, social capital, and opportunities situated in time and space (Bowles 2004, Blau 1994, and Prietula 1994, Carley and Newell 1994, Wallace 1983, Simon 1957). These systematic complications must be related to institutional and organizational contexts (Carroll and Hannan 2000) in complex adaptive systems (Miller and Page 2007). Intergenerational and intragenerational changes in social networks must be dissected, along with their local, intermediate, and global implications outcomes (Oquist and Benner 2012, Nielsen 2012).

- Organizations or institutions, associations or networks, exist in time and space. ${ }^{15}$ These forms of social organization can be conceived mathematically or computationally as cellular automata in whatever society they occur. To probe their formal and informal dimensions as well as the direct and indirect linkages within and across social networks - be they heterogeneous or homogeneous-we must develop the mathematics of cellular automata across iterations (decades or designated time periods), Monte Carlo simulations may allow us to replicate observed differences between colleges and universities over time. Moreover, we must probe whether genetic algorithms and simulated annealing have any role in explaining perturbations, permutations, and

\footnotetext{
${ }^{14}$ Cellular automaton: A mathematical construction consisting of a system of entities, called cell, whose temporal evolution is governed by a collection of rules, so that its behavior over time may appear to be highly complex or chaotic (source: McGraw-Hill Dictionary of Scientific and Technical Terms, $5^{\text {th }}$ ed.). Genetic algorithm: a class of adaptive stochastic optimization algorithms involving search and optimization (source: Wolfram Alpha). Simulated Annealing: An algorithm for optimization problems that become unmanageable using combinatorial methods as the number of objects becomes large (source: Wolfram Alpha).

${ }^{15}$ To be comprehensive in scope, this preliminary analysis must intersect coherently with concepts and measures deduced from Tables 1 and 2. Also, contractual agreements must be incorporated whenever they establish preferential attachments or preference orders among social networks or collectivities.
} 
observed transformations in these cellular automata (Gilbert and Triotzsch 1999). Also, we must determine if the social networks of social agents nested with our cellular automata are amenable to string theory or superstring theory as well as multiples thereof (Becker et al. 2007).

- To reiterate, the corresponding nexus between social networks and organizations must be explicated by mathematical thinking to determine the core, periphery, and semi-periphery of academic systems or global science (including SL).

- Each sector must be modeled with regard to dimensions, formal and informal. Research universities or institutes, doctoral universities, liberal arts colleges, and community colleges imply different imply cellular automata, plus evolutionary processes - for each institutional domain, public or private.

- Cellular automata may be linked by consortia, associations, recruitment networks, as well as, chains of mobility between faculty, administrators, trustees, and students. These social divisions or units [plus their structures, processes, and outcomes] must be modeled in the time and space they emerge. Self-organization, hubs, bursts, bifurcations, oscillations, fractals, growth, atrophy, synchrony, and nonlinear dynamics must be captured in these dynamic systems.

- Each division and dimension must be mapped algebraically according to levels: horizontal and vertical (Pattison 1993).

- Dimensions, divisions, and levels have regions of social exchanges in multidimensional time and space that correspond to markets. Beyond a mere fascination with myopic linear econometric models, these phenomena must be elucidated mathematically (Simon 1995).

- Like physicists or astrophysicists, we must model all these phenomena cumulatively according to their particular states and phase transitions (Casti 1992a, 1992b, Weidlich and Haag 1983).

- These phase transitions relate to sociodynamics (Weidlich 2000, Weidlich and Haag 1980) in ideological or political fields of thinking. Altogether, these complex social phenomena must be carefully mapped and compared across societies before true parsimony is possible (Wilkinson and Pickett 2010, Ben-David 1984).

- Lastly, resource flows, sponsorship networks, and social capital ${ }^{16}$ from professional associations, agencies like the National Science Foundation, and philanthropic foundations must be incorporated in our mathematical systems - along with the set of interconnections with industries or other sponsors (individual and collective). Without incorporating kinship networks, our work will remain insufficient.

In sum, these are the core features that must be modeled mathematically to understand the agents, structures, processes, and outcomes that affect the

\footnotetext{
${ }^{16}$ I prefer Daniel Goleman's (2006) concept of "social intelligence" rather than the traditional concept of social capital. The latter term is used here for convenience and ease in communication.
} 
dispersion and distribution of SL in the United States (Castellani and Hafferty 2009, Casti 1994).

On a more proximate or practical level, advocates of SL for ethnic minority groups need those who would:

- Invest in SL for future generations, especially disadvantaged ethnic groups (including mentorship and sponsorship networks/programs)

- Involve these groups in the synergy and collaboration of invisible colleges (see Israel's Technion for a concrete example)

- Incorporate new communities of practice for SL (Blau 1994). Develop wasted potential in unexpected persons or groups (as Einstein did by locating energy in matter!)

- Investigate salient scientific topics (upgrade the social sciences!)

- Increase incredible outcomes (scientific breakthroughs) in unexpected places and ways.

Science exists to unmask intellectual gullibility in any society (Barrow 2007, Lightman 2005). While SL is not perfect as a truth-seeking strategy, it does move its adherents and humanity beyond the prevalent cognitive schemas (Michie and Cooper 2015). Popular thinking, in and outside the academy, is infused with selective perceptions, biased data, specious evidence, ethnocentric perspectives, conditional fallacies, and ex post facto inferences. Much of humanistic scholarship and deliberations conceals propositional logics, inconclusive determinism, and untested presuppositions (Gowers 2008). Historical or literary articulations often disconnect idiosyncratic interpretations from validity, reliability, and falsification (Michie and Cooper 2015). Political and media discourses are replete with such vacuous pretensions, joining and juggling a cacophony of nonsensical polemics (Kuhn and Nasar 2002, Nash 1996). Only SL helps a neophyte to vitiate these reductive or redundant schemas by connecting conceptualization and measurement protocols under varying conditions (Mitchell 1996) (via trans-subjective peer review within various scientific communities). While admittedly not everything is amenable to SL, useful approximations are frequently viable candidates for discovery and innovation (Ackoff 1974). In closing, let us heed the wisdom of Nobel Laureate (and civil rights icon) Dr. Martin Luther King, Jr. "society must guard against moralistic ignorance and conscientious stupidity". Across the six decades of my life in the United States, I might add as well: society must guard against the entrenched, protracted, vested, interests that promote corresponding ideas that undermine SL!

\section{References}

Ackoff R (1974) Redesigning the Future. New York: John Wiley and Sons. Alumkal A (2017) Paranoid Science. New York: New York University Press. 
American Council on Education and American Association of University Professors (2000) Does Diversity Make a Difference? Washington, D.C.: American Council on Education and American Association of University Professors.

Bailey K (1994) Sociology and the New Systems Theory. Albany: State University of New York.

Barabasi A (2016) Network Science. New York: Cambridge University Press.

Barr D (2014) Health Disparities in the United States, $2^{\text {nd }}$ ed. Baltimore, MD: Johns Hopkins University Press.

Barrow J (2007) New Theories of Everything. New York: Oxford University Press.

Batty M (2005) Cities and Complexity. Cambridge, MA: MIT Press.

Becker K, Becker M, Schwarz J (2007) String Theory and M-Theory. New York: Cambridge.

Ben-David J (1984) The Scientist's Role in Society. Chicago: University of Chicago Press.

Berkman L, Kawachi I (eds) (2000) Social Epidemiology. New York: Oxford University Press.

Best J (2011) The Stupidity Epidemic. New York: Routledge.

Blalock H (1984) Basic Dilemmas in the Social Sciences. Beverly Hills: Sage.

Blalock H (1982) Conceptualization and Measurement in the Social Sciences. Beverly Hills: Sage.

Blalock H, Wilken P (1979) Intergroup Processes. New York: Free Press.

Blalock H, et al. (eds) (1975) Quantitative Sociology. New York: Academic Press.

Blalock H (1969) Theory Construction: From Verbal to Mathematical Formulations.

Blalock H (1964) Causal Inferences in Nonexperimental Research. Chapel Hill: University of North Carolina Press.

Blau P (1994) Structural Contexts of Opportunities. Chicago: University of Chicago Press.

Blau P (1964) Exchange and Power in Social Life. New York: Wiley.

Boorstin D (1983) The Discoverers. New York: Random House.

Borgatti S, Mehra A, Brass D, Lablanca G (2009) Network Analysis in the Social Sciences. SCIENCE 23: 892-895.

Bowles S (2004) Microeconomics. Princeton: Princeton University Press.

Boyd L, Iverson G (1979) Contextual Analysis. Belmont, CA: Wadsworth.

Brandt C (2007) Scientific Discourse in the Academy: A Case Study of an American Indian Undergraduate. Published online 27 December in Wiley InterScience.

Bybee R (2009) PISA's 2006 Measurement of Scientific Literacy: An Insider's Perspective for the U.S. Washington, D.C.: National Institute for Educational Policy.

Byers W (2015) Deep Thinking. New Jersey: World Scientific.

Byers W (2011) The Blind Spot. Princeton: Princeton University Press.

Byers W (2007) How Mathematicians Think. Princeton, NJ: Princeton University Press.

Caliendo S (2015) Inequality in America. Boulder, CO: Westview Press.

Camerer C (2003) Behavioral Game Theory. Princeton: Princeton University Press.

Carley K, Prietula M (1994) Computational Organization Theory. Hillsdale, NJ: Lawrence Erlbaum Associates, Publishers.

Carley K, Newell A (1994) The Nature of the Social Agent. Journal of Mathematical Sociology 19: 221-262.

Carroll G, Hannan M (2000) The Demography of Corporations and Industries. Princeton: Princeton University Press.

Castellani B, Hafferty F (2009) Sociology and Complexity Science. Berlin: SpringerVerlag.

Casti J (1994) Complexification. New York: HarperCollins. 
Casti J (1992a) Reality Rules I. New York: Wiley.

Casti J (1992b) Reality Rules II. New York: Wiley.

Christakis N, Fowler J (2009) Connected. New York: Little, Brown and Co.

Cole J, Cole S (1973) Social Stratification in Science. Chicago: University of Chicago Press.

Estrada E (2012) The Structure of Complex Networks. New York: Oxford University Press.

Feagin J (1994) Racial and Ethnic Relations. Englewood Cliff, NJ; Prentice Hall.

Frey W (2015) Diversity Explosion. Washington, D.C.: Brookings Institution.

Gilbert N, Triotzsch K (1999) Simulation for the Social Scientist. Philadelphia: Open University Press.

Goleman D (2006) Social Intelligence. New York: Bantam Books.

Gould S (1996) The Mismeasure of Man. New York: WW Norton \& Company.

Gowers T (ed) (2008) Princeton Companion to Mathematics. Princeton, NJ: Princeton University.

Gross P, Levitt N, Lewis M (eds) (1996) The Flight from Science and Reason. New York: New York Academy of Sciences.

Gross P, Levitt N (1994) Higher Superstition. Baltimore: Johns Hopkins University Press.

Hazen R, Trefil J (2009) Science Matters. New York: Anchor Books.

Hoff K, Stiglitz J (2016) Striving for Balance in Economics: Towards a Theory of the Social Determination of Behavior. Journal of Economic Behavior and Organization 126: 25-57.

Harvard Business School (2016) Problems Unsolved and a Nation Divided.

Holzman M (2014) The Chains of Black America. Briarcliff Manor, NY: Chelmsford Press.

Hunt E (2007) The Mathematics of Behavior. New York: Cambridge University Press.

Institute for Research on Race and Public Policy, University of Illinois, Chicago (2017) A Tale of Three Cities: The State of Racial Justice in Chicago Report.

Kemeny J (1969) The Social Sciences Call on Mathematics. In G.A.W. Boehm (ed) The Mathematical Sciences, National Research Council, Committee on Support of Research in the Mathematical Sciences (COSRIMS), 21-36. Cambridge, MA: MIT Press.

Kuhn H, Nasar S (eds) (2002) The Essential John Nash. Princeton: Princeton University Press.

Lightman A (2005) The Discoveries. New York: Pantheon.

Mazzucato M (2013) The Entrepreneurial State. London: Anthem Press.

Michie J, Cooper C (eds) (2015) Why the Social Sciences Matter. New York: Palgrave MacMillan.

Miller J, Page S (2007) Complex Adaptive Systems. Princeton: Princeton University Press.

Mitchell M (1996) An Introduction to Genetic Algorithms. Cambridge, MA: MIT Press.

Nash J (1996) Essays on Game Theory. Cheltenham, UK: Edward Elgar.

National Academy of Sciences (NAS), United States (2017a) Examining the Mistrust of Science. Washington, D.C.: National Academies Press.

National Academy of Sciences, United States (2017b) Communicating Science Effectively: A Research Agenda. Washington, D.C.: National Academies Press.

National Academy of Sciences, United States (2016) Science Literacy: Concepts, Contexts, and Consequences. (Prepublication copy) Washington, D.C.: National Academies Press.

National Academy of Sciences, United States (2010) Expanding Underrepresented 
Minority Participation: America's Science and Technology Talent at the Crossroads. (prepublication copy). Washington, D.C.

National Center for Education Statistics, United States Department of Education (2016) "Status and Trends in the Education of Racial and Ethnic Groups 2016." Washington, D.C.: Institute of Education Sciences.

Nielsen M (2012) Reinventing Discovery. Princeton: Princeton University Press.

Oquist G, Benner M (2012) Fostering Breakthrough Research: A Comparative Study. Stockholm, Sweden: Royal Swedish Academy of Sciences.

Otto S (2016) The War on Science. Minneapolis, MN: Milkweed Editions.

Padgett J, Powell W (2012) The Emergence of Organizations and Markets. Princeton: Princeton University Press.

Page S (2007) The Difference. Princeton: Princeton University Press.

Pattison P (1993) Algebraic Models for Social Networks. New York: Cambridge University.

Pew Research Center (2015a) The Race Gap in Science Knowledge. Retrieved from $\mathrm{http}: / /$ pewrsr.ch/1KQBRWW.

Pew Research Center (2015b) A Look at What the Public Knows and Does Not Know About Science.

Piel G (2001) The Age of Science. New York: Basic Books.

Porter M, Onnela J, Mucha P (2009) Communities in Networks. Notices of the American Mathematical Society 56(9):1082-1097.

Royal Society, United Kingdom (2011) Knowledge, Networks, and Nations. London: Royal Society.

Royal Society, United Kingdom (2010) The Scientific Century. London: Royal Society.

Scearce C (2007) Scientific Literacy. Results from the National Science Foundation Science and Engineering Indicators 2006. Released by ProQuest Discovery Guides.

Shapiro D, Dundar A, Huie F, Wakhungu P, Yuan X, Nathan A, Hwang Y (2017) A National View of Student Attainment by Race and Ethnicity-Fall 2010 Cohort (Signature Report No. 12b). Herndon, VA: National Student Clearinghouse Research Center.

Sharkey P (2013) Stuck in Place. Chicago: University of Chicago.

Simon H (1996) The Sciences of the Artificial. Cambridge, MA: MIT Press.

Simon H (1995) Organizations and Markets. Journal of Public Administration Research and Theory 5(3):273-294.

Simon H (1957) Models of Man. New York: Wiley.

Sinatra G, Hofer B (2016) Public Understanding of Science: Policy and Educational Implications. Policy Insights from the Behavioral and Brain Sciences 3(2) 245253.

Smith E, Gunashekar S, Parks S, Lichten C, Lepetit L, Jones M, Manville C, MacLure C (2017) Monitoring Open Science Trends in Europe. Santa Monica, CA: RAND Corporation. Retrieved from http://bit.ly/2inutvb.

Southern Education Foundation (2013) A New Majority: Low Income Students in All Public Schools. Atlanta: Southern Education Foundation.

Tate W (2004) Brown, Political Economy, and the Science Education of African Americans. Review of Research in Education 28(1):147-184.

Thompson D (2008) Counterknowledge. New York: W.W. Norton and Company.

Trefil J (2008) Why Science? New York: Teachers College Press.

UNESCO (2016) UNESCO Science Report: Towards 2030. UNESCO Publishing: Paris, France. 
UNESCO (2010) UNESCO Science Report 2010: The Current Status of Science around the World. UNESCO Publishing: Paris, France.

Valente T (2010) Social Networks and Health. New York: Oxford.

Volti R (1992) Science and Technological Change. New York: St. Martin's Press.

Wagner C (2008) The New Invisible College. Washington, D.C.: Brookings Institution.

Wallace W (1983) Principles of Scientific Sociology. New York: Aldine.

Weidlich W (2000) Sociodynamics. Australia: Harwood Academic Publishers.

Weidlich W, Haag G (1983) Concepts and Methods of a Quantitative Sociology. New York: Springer-Verlag.

Weinberg S (2015) To Explain the World. New York: HarperCollins.

Wilkinson R, Pickett K (2010) The Spirit Level: Why Greater Equality Makes Societies Stronger. New York: Bloomsbury Press.

Wolfram S (2002) A New Kind of Science. Champaign, IL: Wolfram Research.

Wolfram Research. Wolfram Alpha (search engine).

Young H (2001) Individual Strategy and Social Structure. Princeton: Princeton University Press. 